\title{
Altered Serotonin Innervation Patterns in the Forebrain of Monkeys Treated with ( \pm )3,4-Methylenedioxymethamphetamine Seven Years Previously: Factors Influencing Abnormal Recovery
}

\author{
George Hatzidimitriou, ${ }^{1}$ Una D. McCann, ${ }^{2}$ and George A. Ricaurte ${ }^{1}$ \\ ${ }^{1}$ Department of Neurology, The Johns Hopkins Medical Institutions, Baltimore, Maryland 21205, and 2Unit on Anxiety \\ Disorders, Biological Psychiatry Branch, National Institute of Mental Health, Bethesda, Maryland 20892
}

The recreational drug $( \pm) 3,4$-methylenedioxymethamphetamine (MDMA, "Ecstasy") is a potent and selective brain serotonin (5-HT) neurotoxin in animals and, possibly, in humans. The purpose of the present study was to determine whether brain 5-HT deficits persist in squirrel monkeys beyond the 18-month period studied previously and to identify factors that influence recovery of injured 5-HT axons. Seven years after treatment, abnormal brain 5-HT innervation patterns were still evident in MDMA-treated monkeys, although 5-HT deficits in some regions were less severe than those observed at 18 months. No loss of 5-HT nerve cell bodies in the rostral raphe nuclei was found, indicating that abnormal innervation patterns in MDMAtreated monkeys are not the result of loss of a particular 5-HT

The ring-substituted amphetamine derivative ( \pm )3,4-methylenedioxymethamphetamine(MDMA, "Ecstasy") is a recreational drug of abuse that first surfaced in the illicit drug market in the 1980s (Baum, 1985). Since then, MDMA has grown in popularity, not only in the United States but also in Western Europe (Adelekan et al., 1997). Although few formal epidemiological surveys of MDMA use have been conducted, a recent survey found that $2.4 \%$ of college students in the United States had used MDMA during the preceding year (Johnston et al., 1998), more than a fourfold increase from 3 years previously (Johnston et al., 1996). Much of the increased recreational use of MDMA appears to be taking place in the context of large, night-long, social gatherings known as "raves" (Saunders, 1995). During these dance parties, it is not uncommon for individuals to use repeated doses of MDMA, with some subjects reporting use of six to eight doses over a $12-14 \mathrm{hr}$ period.

The increasing recreational use of MDMA is of concern because there is compelling evidence that MDMA can damage brain serotonin (5-HT) neurons in culture (Azmitia et al., 1990), in animals (including nonhuman primates), and possibly in humans (McCann et al., 1994a,b, 1998). Animals treated with MDMA develop long-lasting decreases in regional brain 5-HT, 5-hydroxyindoleacetic acid (Commins et al., 1987; Schmidt, 1987; Ricaurte et al., 1988a; Slikker et al., 1988; Insel et al., 1989),

Received Dec. 17, 1998; revised March 19, 1999; accepted March 25, 1999.

This work was supported by Public Health Service Grants DA05707, DA06275, and DA00206 (G.A.R.) and Intramural Research Program support from the National Institute of Mental Health (U.D.M.).

Correspondence should be addressed to Dr. George A. Ricaurte, Department of Neurology, The Johns Hopkins Medical Institutions, 5501 Hopkins Bayview Circle, Room 5B71E, Baltimore, MD 21224.

Copyright (C) 1999 Society for Neuroscience 0270-6474/99/195096-12\$05.00/0 nerve cell group. Factors that influence recovery of 5-HT axons after MDMA injury are (1) the distance of the affected axon terminal field from the rostral raphe nuclei, (2) the degree of initial 5-HT axonal injury, and possibly (3) the proximity of damaged $5-\mathrm{HT}$ axons to myelinated fiber tracts. Additional studies are needed to better understand these and other factors that influence the response of primate $5-\mathrm{HT}$ neurons to MDMA injury and to determine whether the present findings generalize to humans who use MDMA for recreational purposes.

Key words: amphetamines; methylenedioxymethamphetamine; serotonin; neurotoxicity; regeneration; 5-HT axon

tryptophan hydroxylase (TPH) activity (Stone et al., 1986; Schmidt and Taylor, 1987), and 5-HT transporter density (Battaglia et al., 1987, 1988; Commins et al., 1987). Anatomical studies indicate that these neurochemical deficits are most likely related to a distal axotomy of brain 5-HT neurons (O'Hearn et al., 1988; Wilson et al., 1989; Molliver et al., 1990). Notably, long-term effects of MDMA in nonhuman primates occur after doses of MDMA that are comparable to doses used by some human MDMA users (Ricaurte et al., 1988b; Doblin, 1989).

The fate of brain 5-HT neurons after MDMA injury is of considerable interest, both practically and scientifically. In MDMA-treated rats, the distal axotomy of central 5-HT neurons is usually followed by a gradual sprouting of 5-HT axons that leads to near complete recovery of 5-HT axonal markers in many brain regions 1 year after drug exposure (Battaglia et al., 1988; De Souza et al., 1990; Molliver et al., 1990; Scanzello et al., 1993; Wilson et al., 1993; Axt et al., 1994; Lew et al., 1996; Sabol et al., 1996). In MDMA-treated monkeys, some axonal sprouting also takes place, but reinnervation patterns 18 months after MDMA treatment are abnormal, with some brain regions remaining denervated and others showing evidence of reinnervation (Insel et al., 1989; Ricaurte et al., 1992; Fischer et al., 1995).

The purpose of the present study was to determine whether altered 5-HT innervation patterns persisted beyond the 18 month post-drug survival period studied previously and to identify factors that governed 5-HT axonal regeneration after MDMA injury.

\section{MATERIALS AND METHODS}

Animals. Ten (8 male and 2 female) squirrel monkeys (Saimiri sciureus), ranging in weight from 700 to $1000 \mathrm{gm}$, were used. The precise age of the monkeys was not known because the animals were feral-reared. How- 
ever, all of the animals were in early to mid adulthood at the time of MDMA (or saline) treatment. Monkeys were housed individually in standard steel cages with free access to food (Purina Monkey Chow) and water. The colony room was maintained at $24-26^{\circ} \mathrm{C}$. Fluorescent lighting in the room was automatically turned on daily at 6:00 A.M. and off at 6:00 P.M. The facility for housing and care of the animals is accredited by the American Association for the Accreditation of Laboratory Animal Care. The experimental protocol was approved by the Animal Care and Use Committee of the Johns Hopkins Medical Institutions.

Drug treatment. Racemic MDMA hydrochloride, dissolved in a sterile $0.9 \%$ sodium chloride solution, was injected subcutaneously at a dose of $5 \mathrm{mg} / \mathrm{kg}$ twice daily (9 A.M. and 5 P.M.) for 4 consecutive days. MDMA was administered on a milligram per kilogram basis, with the dose expressed as the hydrochloride salt. This particular dosage regimen of MDMA was selected because it is one that is known to produce moderate to severe 5-HT lesions, depending on brain region (Ricaurte et al., 1988a,b). Control animals received an equivalent volume of saline. Animals tolerated MDMA without any apparent difficulty.

Immunocytochemical studies. Animals were killed 2 weeks $(n=3$ MDMA-treated; $n=2$ saline-treated) and 6-7 years ( $n=3$ MDMAtreated; $n=2$ saline-treated) after drug treatment. One hour before animals were killed, control and experimental animals were pretreated with the monoamine oxidase inhibitor trans-2-phenylcyclopropylamine $(10 \mathrm{mg} / \mathrm{kg}$, i.p.). Intracardiac perfusion was then performed under deep sodium pentobarbital anesthesia $(40 \mathrm{mg} / \mathrm{kg})$. After the vasculature was cleared with $850 \mathrm{ml}$ of ice-cold PBS, the perfusion was continued with $3600 \mathrm{ml}$ of cold $4 \%$ paraformaldehyde and $0.12 \%$ glutaraldehyde in 0.15 M phosphate buffer, $\mathrm{pH}$ 7.4. Tissue blocks were placed in buffered $4 \%$ paraformaldehyde for 6-7 hr and then in 10\% dimethylsulfoxide in PBS overnight. Blocks were frozen-sectioned $(30 \mu \mathrm{m})$ using a sliding microtome and collected in cold PBS. Free-floating sections were incubated at $4^{\circ} \mathrm{C}$ for $60 \mathrm{hr}$ with the following antisera: rabbit anti-5HT diluted 1:14,000 in PBS with $0.2 \%$ Triton X-100 and $1 \%$ normal goat serum; mouse anti-tyrosine hydroxylase (TH) diluted 1:5000 in PBS with $0.2 \%$ Triton X-100 and 1\% normal horse serum; and sheep anti-tryptophan hydroxylase (TPH) diluted 1:20,000 in PBS with $0.3 \%$ Triton X-100, $2 \%$ normal rabbit serum, and $0.25 \%$ gelatin. Tissue sections labeled with the tryptophan hydroxylase antibody were pretreated for $1 \mathrm{hr}$ in PBS containing $0.5 \%$ gelatin, $2 \%$ normal rabbit serum, and $0.3 \%$ Triton X-100. Bound immunoglobulins were visualized with the Vectastain ABCperoxidase method, and staining was enhanced with the osmiophilic reaction sequence of Gerfen (1985). The demarcation of cellular laminae was determined in adjacent sections with $0.5 \%$ cresyl violet.

Anatomic analysis. Details of the regional anatomy of the squirrel monkey brain were based on the atlas of Emmers and Akert (1963). Specific brain regions and their respective locations are summarized in Table 1. Matched coronal sections of the brain were evaluated with a Zeiss Axioplan microscope using dark-field illumination. A quantitative analysis of the density of axonal fields was performed with the aid of an MCID-M1 (version 5.0, rev. 2.0) image analysis system (Imaging Research, Brock University, St. Catherines, Ontario, Canada). Microscope images were digitized with a CCD 72 camera (Dage-MTI, Michigan City, IN). The grain counting program that was used was determined to be linear across the range of illumination intensities seen through the microscope. A segmentation range (i.e., range of densities between an upper and lower threshold) was established to discriminate between target and background. All pixels whose density lies within the segmentation range were considered valid targets. For each anatomic region examined, the microscope illumination and video camera gain (and black level) were adjusted to eliminate any nonspecific background material. Thereafter, these parameters were kept constant for each animal. Several digitized images from each region were collected at $5 \times$ or $10 \times$ magnification (depending on the size of the region). Each image was scanned and analyzed to determine total grains per unit area. These data were used to calculate percentage differences between treated and control animals. By necessity, each monkey was killed and processed individually because of the labor-intensive nature of the immunocytochemical staining procedure. Although tissue sections were always processed in an identical manner, the sometimes capricious nature of the technique can occasionally result in variable degrees of staining. The amount of reaction product localized on 5-HT axons can also influence the estimate of axonal density, because the grain-counting algorithm that was used measures any illuminated objects that appear in a given area. Therefore, to minimize potential error secondary to differences in immunocytochemical staining intensity, monkeys from each treatment group were
Table 1. Location of brain regions analyzed

\begin{tabular}{|c|c|c|}
\hline Brain region & $\begin{array}{l}\text { Anterior- } \\
\text { posterior } \\
\text { level }(\mathrm{mm})^{a}\end{array}$ & $\begin{array}{l}\text { Sample } \\
\text { no./level }\end{array}$ \\
\hline Frontal cortex (CFA) & A15.0 & 4 \\
\hline Cingulate cortex (CCA) & A15.0 & 3 \\
\hline Temporal cortex (CTp) & A10.5, A8.0 & 4,4 \\
\hline Insular cortex (CIs) & A10.5, A8.0 & 3,3 \\
\hline Pyriform cortex (CPf) & $\mathrm{A} 10.5, \mathrm{~A} 8.0$ & 2,2 \\
\hline Parietal cortex $\mathrm{CPa}$ ) & A 8.0 & 4 \\
\hline Primary visual cortex (CSt) & LR9. $0^{c}$ & 3 \\
\hline Caudate $(\mathrm{Cd})$ & $\begin{array}{l}\text { A15.0, A10.5 } \\
\text { A8.0 }\end{array}$ & $3,3,2$ \\
\hline Putamen (Put) & $\begin{array}{l}\text { A15.0, A10.5, } \\
\text { A8.0 }\end{array}$ & $3,4,4$ \\
\hline Globus pallidus (GP) & A10.5 & 4 \\
\hline Septum, dorsal (DS) & A15.0 & 1 \\
\hline Septum, lateral (LS) & A15.0 & 1 \\
\hline Olfactory tubercle, plexiform (TOf) & A15.0 & 1 \\
\hline Olfactory tubercle, polymorphic (TOm) & A15.0 & 1 \\
\hline Accumbens (ASt) & A15.0 & 1 \\
\hline Insula Calleja (IC) & A15.0 & 4 \\
\hline Amygdala, basal medial accessory (BAM) & A10.5 & 1 \\
\hline Amygdala, basal lateral accessory (BAL) & A10.5 & 1 \\
\hline Amygdala, basal lateral (BLA) & A10.5 & 1 \\
\hline Amygdala, basal medial (BMA) & A10.5 & 1 \\
\hline Amygdala, central (CeA) & A10.5 & 1 \\
\hline Amygdala, lateral (LA) & A10.5 & 1 \\
\hline Hypothalamus, dorsal (ADH) & A10.5 & 1 \\
\hline Hypothalamus, dorsal medial (DmH) & A10.5 & 1 \\
\hline Hypothalamus, ventral medial $(\mathrm{VmH})$ & A10.5 & 1 \\
\hline Hypothalamus, lateral (ALH) & A10.5 & 1 \\
\hline Thalamus, ventral anterior (VA) & A10.5 & 1 \\
\hline Thalamus, anterior ventral (AV) & A10.5 & 1 \\
\hline Thalamus, lateral dorsal (LD) & A 8.0 & 1 \\
\hline Thalamus, medial dorsal (MD) & A 8.0 & 1 \\
\hline Thalamus, ventral lateral, pars oralis (VLo) & A 8.0 & 1 \\
\hline Thalamus, ventral lateral (VL) & A 8.0 & 1 \\
\hline Thalamus, ventral posterior inferior (VPI) & A 8.0 & 1 \\
\hline Zona incerta $(\mathrm{ZI})$ & A 8.0 & 1 \\
\hline Mammillary body, medial (MM) & A 8.0 & 2 \\
\hline Hippocampus, dentate (FD) & A 8.0 & 2 \\
\hline Hippocampus, (CA1) & A 8.0 & 2 \\
\hline Hippocampus, (CA2) & A 8.0 & 1 \\
\hline Hippocampus, (CA3) & A8.0 & 2 \\
\hline Subiculum (Sbc) & A8.0 & 1 \\
\hline
\end{tabular}

$\overline{\left.{ }^{a} \text { Coronal plane based on the anterior-posterior zero plane (AP } 0.0\right) \text { that cuts across }}$ the cranium at the level of the external auditory meatuses (Emmers and Akert, 1963).

${ }^{b}$ Number of microscopic fields used to collect data for each region using the MCID image analysis system.

${ }^{c}$ Sagittal plane based on the left-right zero plane (LR 0.0) that bisects the cranium at the midpoint into two symmetrical halves (Emmers and Akert, 1963).

selected at random during the course of the analysis, thereby avoiding systematic differences in staining intensities for animals in each group.

Cell counts. Quantification of cell bodies in the raphe nucleus was also performed with the MCID image analysis system. Carefully matched representative levels of the dorsal, median, and B9 cell groups were selected using the third nerve nucleus, the medial longitudinal fasciculi, and the size and shape of the aqueduct as reference points. The dorsal and median raphe nuclei were counted separately because of differences in the density of cells and background staining. Under bright-field illu- 
mination and low-power magnification $(2.5 \times)$, each nucleus was digitized after the microscope illumination was adjusted to differentiate cell bodies from background. A mean cell body area was determined to allow the number of clumped cells to be estimated. A minimum area was selected to exclude stained axons and dense artifacts. After a field was digitized, cells were scanned by the imaging program that differentiated counted cells from excluded objects. Raphe nuclei were then reexamined under high magnification and compared with the scanned image to remove or add discrete targets missed by the scan. Nerve cell bodies in raphe nuclei were also counted manually while the specimen was examined under the microscope to assure accurate counts. Because the material was not collected in such a way as to permit unbiased stereology, this method of cell counting was not used.

Statistical analysis. Results were evaluated by ANOVA. When statistical differences were observed, post hoc comparisons were performed with Duncan's multiple range tests, compensating for multiple comparisons. Spearman's correlations were used to calculate the relation between the distance of the terminal field from the rostral raphe and recovery at 7 years, and lesion size and extent of recovery at 7 years. All tests were two-tailed, and significance was set at $p \leq 0.05$. Data analysis was performed using the Statistical Program for the Social Sciences (SPSS for Windows, Release 6).

Drugs and chemicals. MDMA-HCl (molecular weight 229.71) was provided by the National Institute of Drug Abuse. trans-2phenylcyclopropylamine was purchased from Regis Chemical (Morton Grove, I1). 5-HT and TH antibodies were obtained from Incstar (Stillwater, $\mathrm{MN}$ ), and $\mathrm{TPH}$ antibody was obtained from Chemicon International (Temecula, CA).

\section{RESULTS}

Regional densities of 5-HT immunoreactive (IR) axons in the brains of control animals $(n=4)$ and animals treated with MDMA 2 weeks $(n=3)$ and 6.5-7 years previously (hereafter referred to as 7 year survivors; $n=3$ ) are shown in Table 2. There were no obvious differences between controls examined 2 weeks $(n=2)$ and 7 years $(n=2)$ after saline treatment, suggesting that within the time frame of the study, no significant changes in 5-HT-IR axon density occurred as a result of aging.

\section{Method validation}

To assess the reliability of the method used here to measure 5-HT-IR axon density, we compared the present 2 week results with those obtained previously in MDMA-treated squirrel monkeys with an identical experimental history and survival time, but we evaluated for 5-HT axon loss using HPLC-electrochemical detection (EC) methods (Ricaurte et al., 1992; Fischer et al., 1995). The findings with the two methods were quite comparable, as evidenced by the high correlation between the degree of 5-HT axonal loss detected with the present immunocytochemical method and the previous HPLC-EC method $(r=0.79, p<0.01)$. These observations attest to the validity and reliability of the present method for measuring regional brain 5-HT axon density. Results are summarized by brain region below.

\section{Neocortex}

Two weeks after MDMA treatment, there were pronounced (83-95\%) reductions in 5-HT-IR axon density in all areas of cerebral cortex examined (Fig. 1, Table 2). In frontal and parietal cortical regions, spared 5-HT axons exhibited a medial to lateral gradient, with greater fiber density evident in the lateral opercular cortex, when viewed in coronal sections. In cingulate, insular, and pyriform cortical regions, some spared axons were evident in layers I and II (data not shown). Spared axons in the primary visual cortex were located predominantly in layer IV (Fig. 1).

Seven years after MDMA treatment, 5-HT axon density remained decreased in all neocortical regions examined (Fig. 1, Table 2), although there was significant recovery relative to the 2 week survivors. In general, all neocortical cell layers appeared equally denervated. However, in the primary visual cortex and occipital cortical regions, the largest reduction in fibers was evident in layer $I_{C}$. The decrease in density of layer $I_{C}$ is such that it is no longer discernible as a distinct layer in MDMAtreated monkeys after a 7 year survival period (Fig. 1).

\section{Hippocampal formation}

\section{$C A 1-C A 3$}

Two weeks after MDMA treatment, reductions in 5-HT axon density were apparent in all three fields of the hippocampus (Fig. 2, Table 2). In 7 year survivors, significant decreases in 5-HT axon density were still apparent in CA1 and CA2, although some recovery was evident in CA3. The molecular layer, although severely reduced in density, once again becomes apparent as a distinct band in the CA2 region of 7 year survivors (Fig. 2).

\section{Dentate gyrus}

Despite similar overall depletions of 5-HT-IR in 2 week and 7 year survivors (Table 2), the pattern of serotonergic innervation in the two groups differs. In particular, in 2 week survivors the dentate hilus has a moderate density of spared 5-HT axons compared with the molecular layer, which is severely denervated (Fig. 2). In contrast, among 7 year survivors, the hilus has fewer axonal fibers present, whereas the molecular layer shows some recovery in axon density (Fig. 2).

\section{Subiculum}

Two weeks after MDMA treatment, there is a $93 \%$ decrease in 5-HT-IR axon density in the subiculum, with a small number of axons remaining in the molecular layer (Fig. 3). Of all the brain regions examined in this study, the subiculum shows the largest reduction $(80 \%)$ ) for 7 year survivors.

\section{Striatum}

\section{Caudate}

The caudate nucleus was sampled at three different coronal levels representing the head and body. Two weeks and 7 years after MDMA treatment, all regions of the caudate nucleus examined showed substantial reductions in 5-HT-IR axon density, with evidence of partial recovery by 7 years (Fig. 4, Table 2).

\section{Putamen}

The putamen was likewise sampled at three different levels. Two weeks and 7 years after MDMA treatment, reductions in 5-HT axon density are evident. Again, there was evidence of partial recovery by 7 years (Table 2).

\section{Globus pallidus}

Estimates of 5-HT axon density in the globus pallidus (GP) were also based on examination of at least three levels. In all animals, including controls, the rostral part of the globus pallidus contained the highest density of 5-HT axons, with decreasing numbers of axons occurring caudally. Two weeks after MDMA, there was a reduction in 5-HT axon density throughout the length of the globus pallidus, with a more profound reduction evident in the external segment (Fig. 5, Table 2). In 7 year survivors, both 


\begin{tabular}{|c|c|c|c|c|c|}
\hline Region & Control $\left(10^{2}\right)$ & MDMA-2 weeks $\left(10^{2}\right)$ & $\%$ Control & MDMA-7 years $\left(10^{2}\right)$ & $\%$ Control \\
\hline \multicolumn{6}{|c|}{ Neocortex } \\
\hline CFA & $647 \pm 22$ & $42 \pm 10$ & $7^{a, c}$ & $410 \pm 73$ & $63^{a, b}$ \\
\hline $\mathrm{CCA}$ & $753 \pm 31$ & $96 \pm 34$ & $13^{a, c}$ & $467 \pm 52$ & $62^{a, b}$ \\
\hline CTp1 & $597 \pm 46$ & $31 \pm 8$ & $5^{a, c}$ & $361 \pm 44$ & $60^{a, b}$ \\
\hline $\mathrm{CTp} 2$ & $621 \pm 70$ & $36 \pm 11$ & $6^{a, c}$ & $385 \pm 46$ & $62^{a, b}$ \\
\hline CIs1 & $812 \pm 34$ & $118 \pm 21$ & $15^{a, c}$ & $526 \pm 40$ & $65^{a, b}$ \\
\hline CIs2 & $841 \pm 22$ & $125 \pm 31$ & $15^{a, c}$ & $559 \pm 11$ & $66^{a, b}$ \\
\hline CPf1 & $833 \pm 30$ & $144 \pm 18$ & $17^{a, c}$ & $477 \pm 63$ & $57^{a, b}$ \\
\hline $\mathrm{CPf} 2$ & $786 \pm 72$ & $116 \pm 20$ & $15^{a, c}$ & $343 \pm 46$ & $44^{a, b}$ \\
\hline $\mathrm{CPa}$ & $640 \pm 49$ & $70 \pm 20$ & $11^{a, c}$ & $415 \pm 30$ & $65^{a, b}$ \\
\hline $\mathrm{CSt}$ & $758 \pm 60$ & $64 \pm 23$ & $9^{a, c}$ & $347 \pm 14$ & $46^{a, b}$ \\
\hline \multicolumn{6}{|l|}{ Striatum } \\
\hline $\mathrm{Cd} 1$ & $149 \pm 11$ & $10 \pm 0.6$ & $7^{a}$ & $50 \pm 17$ & $34^{a}$ \\
\hline $\mathrm{Cd} 2$ & $210 \pm 11$ & $18 \pm 0.1$ & $9^{a}$ & $51 \pm 5$ & $24^{a}$ \\
\hline $\mathrm{Cd} 3$ & $167 \pm 25$ & $12 \pm 0.2$ & $8^{a}$ & $50 \pm 4$ & $30^{a}$ \\
\hline Put1 & $300 \pm 41$ & $53 \pm 19$ & $18^{a}$ & $155 \pm 56$ & $52^{a}$ \\
\hline Put2 & $251 \pm 13$ & $34 \pm 4$ & $14^{a}$ & $108 \pm 17$ & $43^{a}$ \\
\hline Put3 & $222 \pm 25$ & $34 \pm 4$ & $15^{a}$ & $118 \pm 1.8$ & $53^{a}$ \\
\hline \multicolumn{6}{|c|}{ Globus pallidus } \\
\hline GPex & $527 \pm 20$ & $203 \pm 21$ & $39^{a, c}$ & $1069 \pm 37$ & $203^{a, b}$ \\
\hline GPin & $766 \pm 30$ & $391 \pm 64$ & $51^{a, c}$ & $902 \pm 61$ & $128^{a, b}$ \\
\hline \multicolumn{6}{|c|}{ Limbic regions } \\
\hline DS & $150 \pm 14$ & $85 \pm 21$ & $56^{a}$ & $161 \pm 2$ & $107^{b}$ \\
\hline LS & $273 \pm 33$ & $198 \pm 12$ & 72 & $355 \pm 37$ & $130^{b}$ \\
\hline TOf & $454 \pm 13$ & $97 \pm 10$ & $21^{a, c}$ & $486 \pm 92$ & $107^{b}$ \\
\hline TOm & $325 \pm 33$ & $102 \pm 30$ & $31^{a, c}$ & $339 \pm 48$ & $104^{b}$ \\
\hline $\mathrm{ASt}$ & $384 \pm 41$ & $141 \pm 39$ & $37^{a, c}$ & $398 \pm 56$ & $104^{b}$ \\
\hline BAM & $360 \pm 36$ & $135 \pm 64$ & $38^{a, c}$ & $245 \pm 17$ & 68 \\
\hline BAL & $605 \pm 62$ & $130 \pm 23$ & $22^{a, c}$ & $510 \pm 65$ & $84^{b}$ \\
\hline BLA & $793 \pm 56$ & $228 \pm 12$ & $29^{a, c}$ & $522 \pm 13$ & $66^{a, b}$ \\
\hline BMA & $705 \pm 47$ & $99 \pm 8$ & $14^{a}$ & $262 \pm 50$ & $40^{a}$ \\
\hline $\mathrm{CeA}$ & $494 \pm 61$ & $171 \pm 17$ & $35^{a, c}$ & $487 \pm 46$ & $98^{b}$ \\
\hline LA & $762 \pm 80$ & $34 \pm 8$ & $5^{a}$ & $326 \pm 29$ & $43^{a}$ \\
\hline \multicolumn{6}{|c|}{ Hypothalamus } \\
\hline $\mathrm{ADH}$ & $1114 \pm 16$ & $510 \pm 91$ & $46^{a, c}$ & $999 \pm 123$ & $90^{b}$ \\
\hline $\mathrm{DmH}$ & $1015 \pm 25$ & $619 \pm 96$ & $61^{a}$ & $926 \pm 122$ & 91 \\
\hline $\mathrm{VmH}$ & $934 \pm 82$ & $602 \pm 75$ & $64^{a}$ & $957 \pm 166$ & 102 \\
\hline $\mathrm{ALH}$ & $1127 \pm 92$ & $1111 \pm 103$ & 99 & $1201 \pm 95$ & 107 \\
\hline \multicolumn{6}{|c|}{ Thalamus } \\
\hline VA & $302 \pm 37$ & $63 \pm 11$ & $21^{a, c}$ & $459 \pm 115$ & $152^{a, b}$ \\
\hline $\mathrm{AV}$ & $454 \pm 53$ & $40 \pm 2$ & $9^{a}$ & $250 \pm 16$ & $55^{a}$ \\
\hline LD & $515 \pm 77$ & $35 \pm 5$ & $7^{a}$ & $249 \pm 6$ & 48 \\
\hline MD & $727 \pm 27$ & $82 \pm 3$ & $11^{a, c}$ & $673 \pm 71$ & $93^{b}$ \\
\hline VLo & $586 \pm 14$ & $37 \pm 10$ & $6^{a, c}$ & $642 \pm 137$ & $110^{b}$ \\
\hline VL & $884 \pm 22$ & $64 \pm 5$ & $6^{a, c}$ & $682 \pm 117$ & $77^{b}$ \\
\hline VPI & $290 \pm 31$ & $27 \pm 1$ & $9^{a, c}$ & $366 \pm 38$ & $126^{a, b}$ \\
\hline \multicolumn{6}{|c|}{ Hippocampus } \\
\hline FD & $343 \pm 28$ & $195 \pm 18$ & $57^{a}$ & $190 \pm 47$ & $55^{a}$ \\
\hline CA1 & $273 \pm 23$ & $83 \pm 7$ & $30^{a}$ & $157 \pm 27$ & $57^{a}$ \\
\hline CA2 & $773 \pm 36$ & $365 \pm 54$ & $47^{a}$ & $495 \pm 61$ & $64^{a}$ \\
\hline CA3 & $225 \pm 14$ & $102 \pm 10$ & $46^{a}$ & $149 \pm 40$ & 66 \\
\hline $\mathrm{Sbc}$ & $342 \pm 24$ & $25 \pm 5$ & $8^{a}$ & $67 \pm 24$ & $20^{a}$ \\
\hline \multicolumn{6}{|c|}{ Other regions } \\
\hline ZI & $427 \pm 22$ & $289 \pm 12$ & $68^{a}$ & $475 \pm 39$ & 121 \\
\hline MM & $1239 \pm 72$ & $232 \pm 48$ & $19^{a, c}$ & $623 \pm 49$ & $50^{a, b}$ \\
\hline IC & $18 \pm 3$ & $5 \pm 1$ & $32^{a}$ & $9 \pm 0.1$ & $51^{a}$ \\
\hline
\end{tabular}

MDMA was given subcutaneously at a dose of $5 \mathrm{mg} / \mathrm{kg}$ twice daily for 4 consecutive days. Values represent the mean \pm SEM and are expressed in pixels. ${ }^{a}$ Designates significantly different from control.

${ }^{b}$ Designates significantly different from 2 week survival.

${ }^{c}$ Designates significantly different from 7 year survival. 

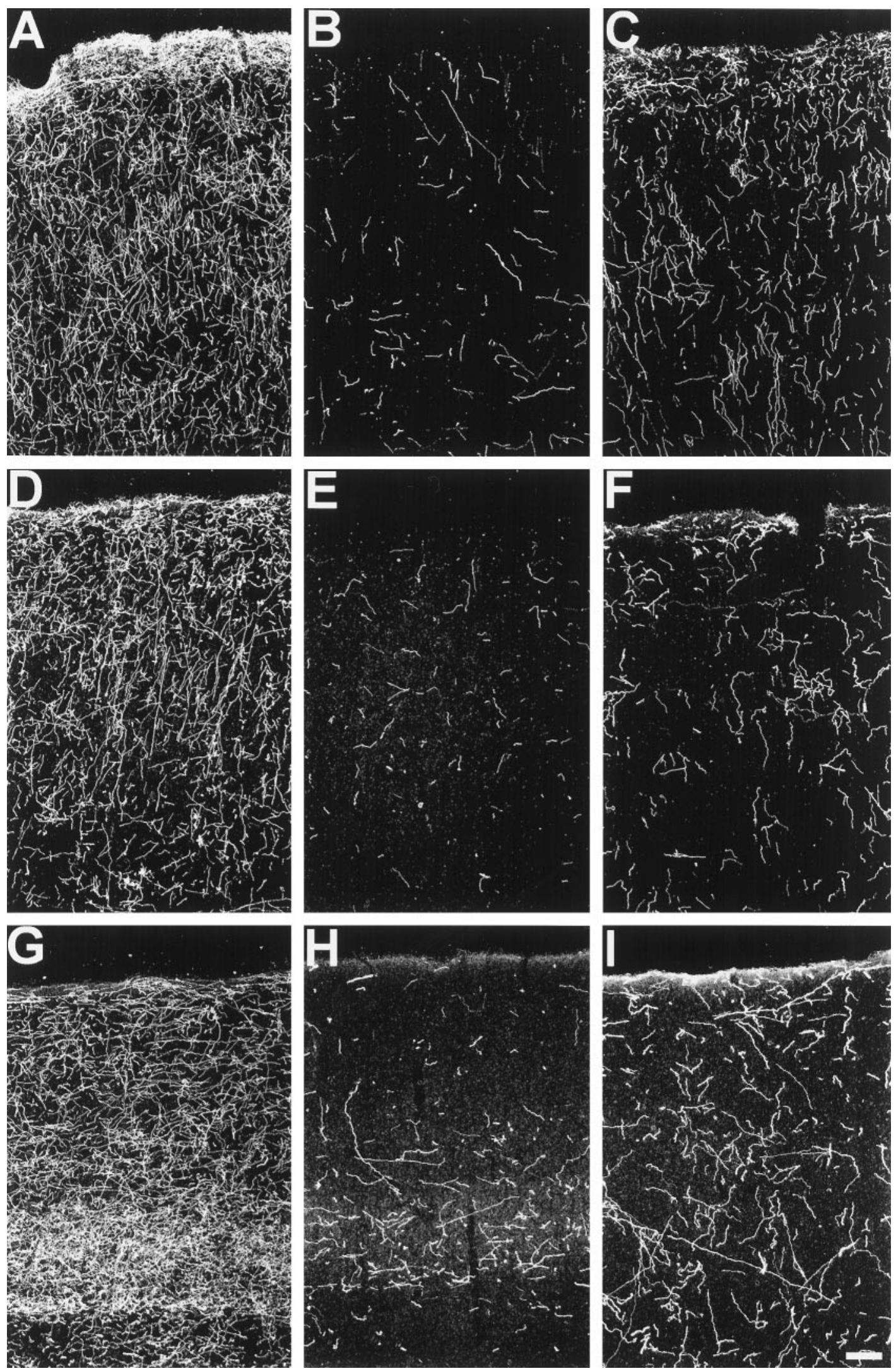

Figure 1. Dark-field photomicrograph, sagittal plane, of 5-HT immunoreactive axons in the frontal, parietal, and primary visual cortex of a control monkey $(A, D, G)$, a monkey treated with MDMA 2 weeks previously $(B, E, H)$, and a monkey treated with MDMA 7 years previously $(C, F, I)$. Note the reduction in axon density 2 weeks after MDMA exposure and the persistent regional deficits in axon density 7 years after MDMA exposure. Scale bar, $100 \mu \mathrm{m}$. 

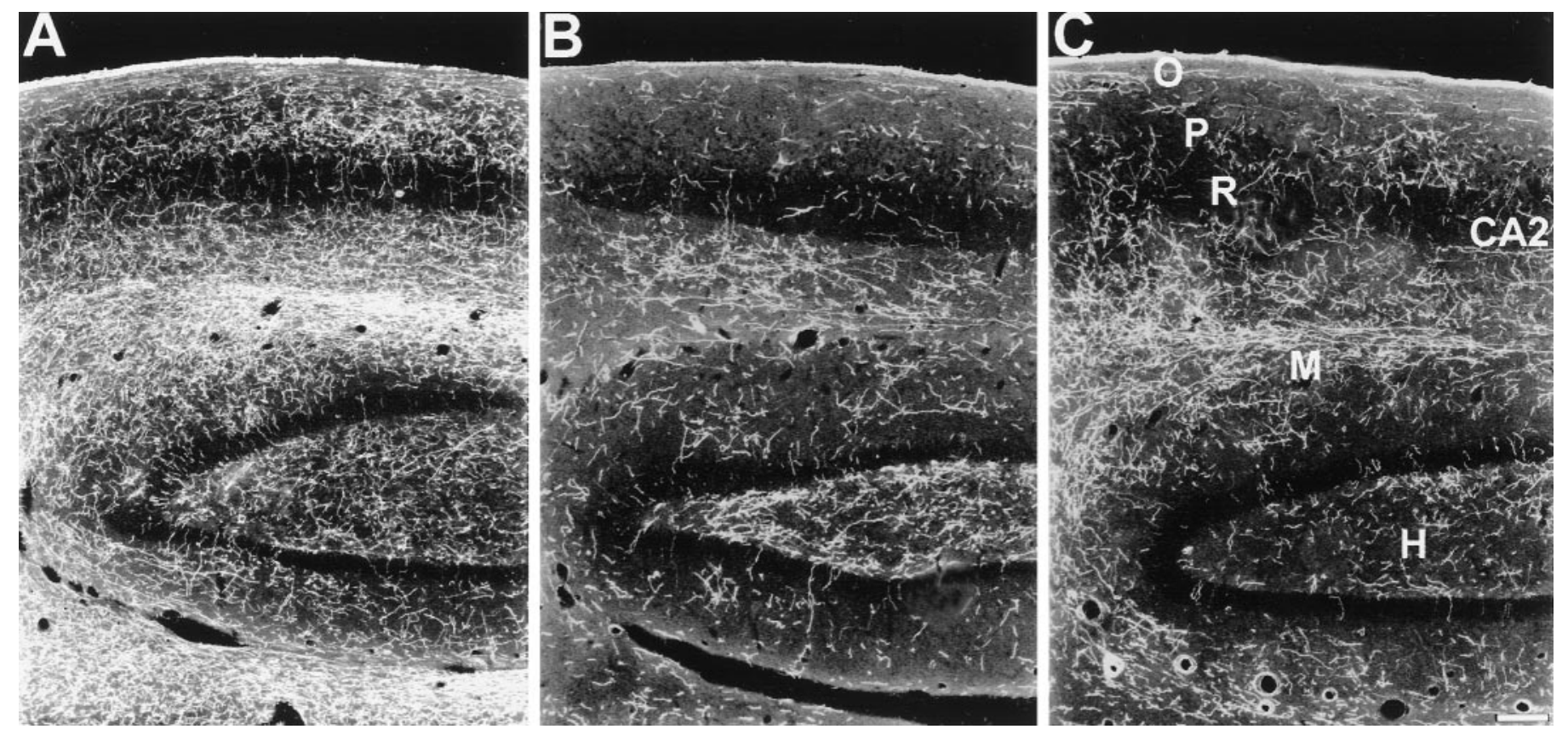

Figure 2. Dark-field photomicrograph, sagittal plane, of 5-HT immunoreactive axons in the hippocampus and dentate gyrus of a control monkey $(A)$, a monkey treated with MDMA 2 weeks previously $(B)$, and a monkey treated with MDMA 7 years previously $(C)$. In both MDMA-treated monkeys, a reduction in axon density is evident in the stratum oriens $(O)$, the stratum pyramidale $(P)$, and the molecular layer $(M)$. Note substantial denervation in the hilus $(H)$ of the 7-year MDMA monkey. Scale bar, $200 \mu \mathrm{m}$.
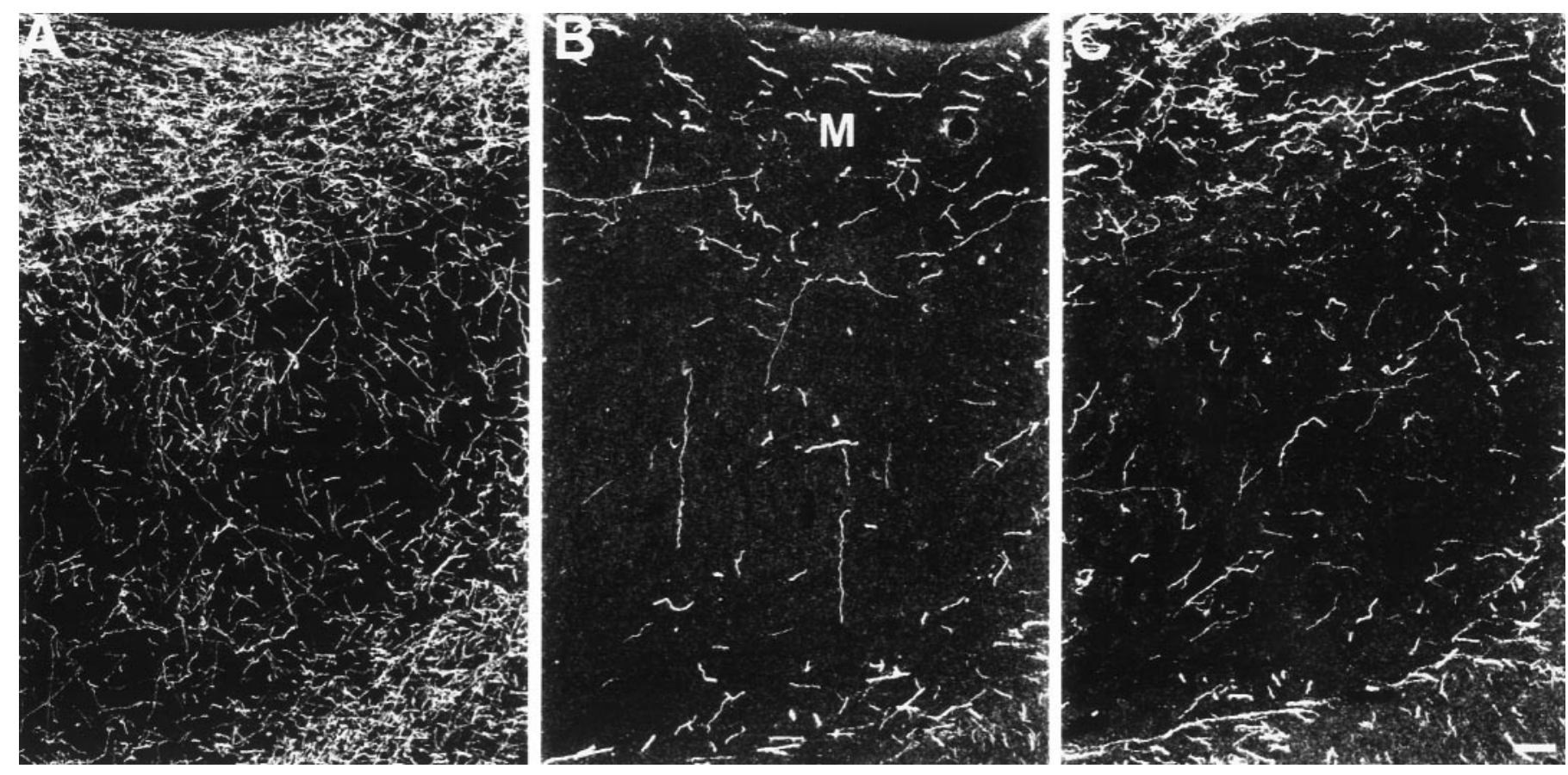

Figure 3. Dark-field photomicrograph, coronal plane, of 5-HT immunoreactive axons in the subiculum of a control monkey $(A)$, a 2 week MDMA monkey $(B)$, and a 7 year MDMA monkey $(C)$. Note the pronounced reduction in axon density still evident 7 years after MDMA treatment. $M$, Molecular layer. Scale bar, $100 \mu \mathrm{m}$.

segments of the globus pallidus show evidence of hyperinnervation, especially the external segment (Table 2). This hyperinnervation was most noticeable along the medial aspect of the globus pallidus adjacent to the internal capsule.

\section{Amygdaloid complex}

Two weeks after MDMA treatment, monkeys exhibit a $62-95 \%$ decrease in 5-HT immunoreactivity among the six nuclei examined (Table 2). The lateral nucleus features the greatest reduction 

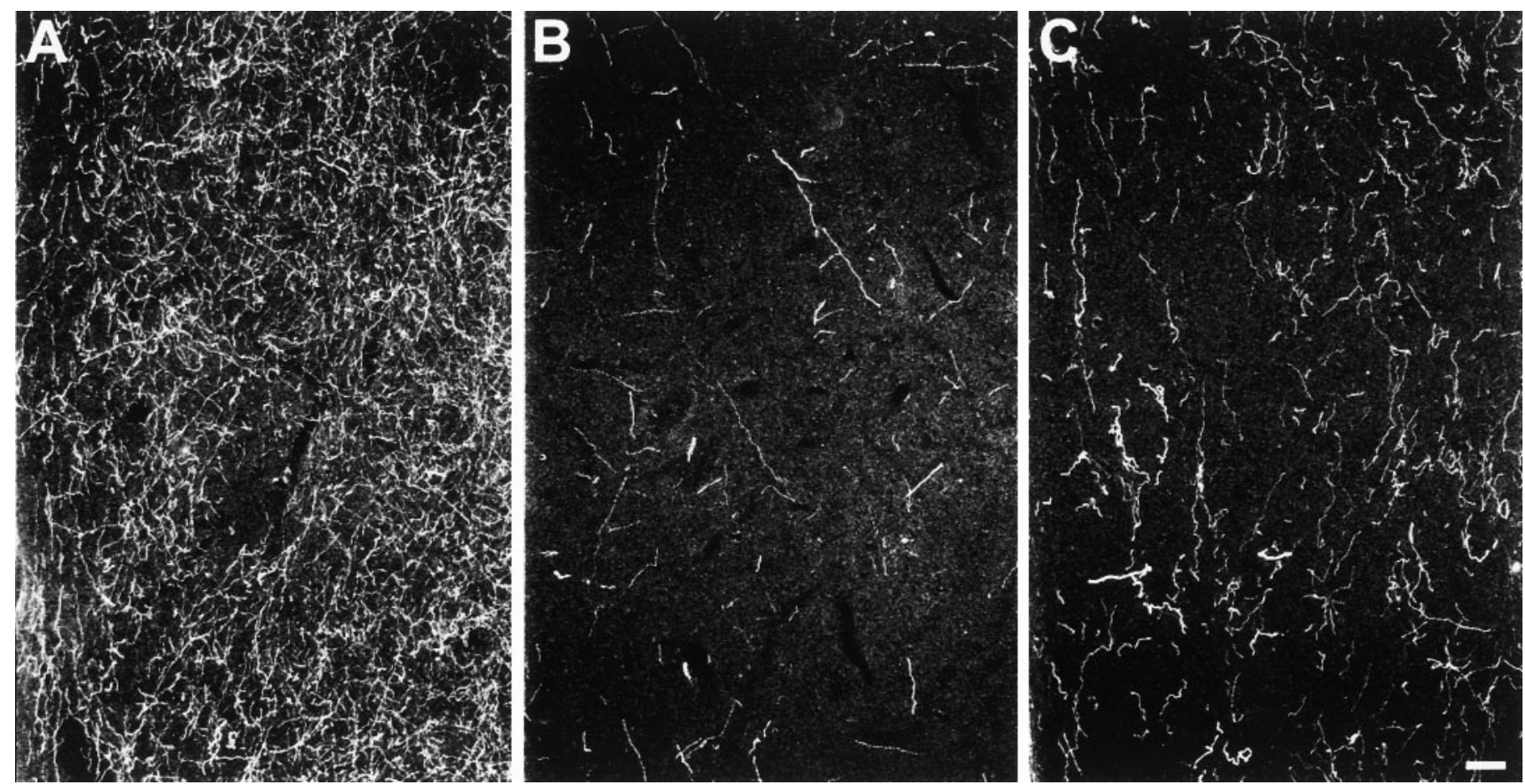

Figure 4. Dark-field photomicrograph, sagittal plane, of 5-HT immunoreactive axons in the caudate nucleus of a control monkey $(A)$, a 2 week MDMA-treated monkey $(B)$, and a 7 year MDMA-treated monkey $(C)$. Scale bar, $100 \mu \mathrm{m}$.
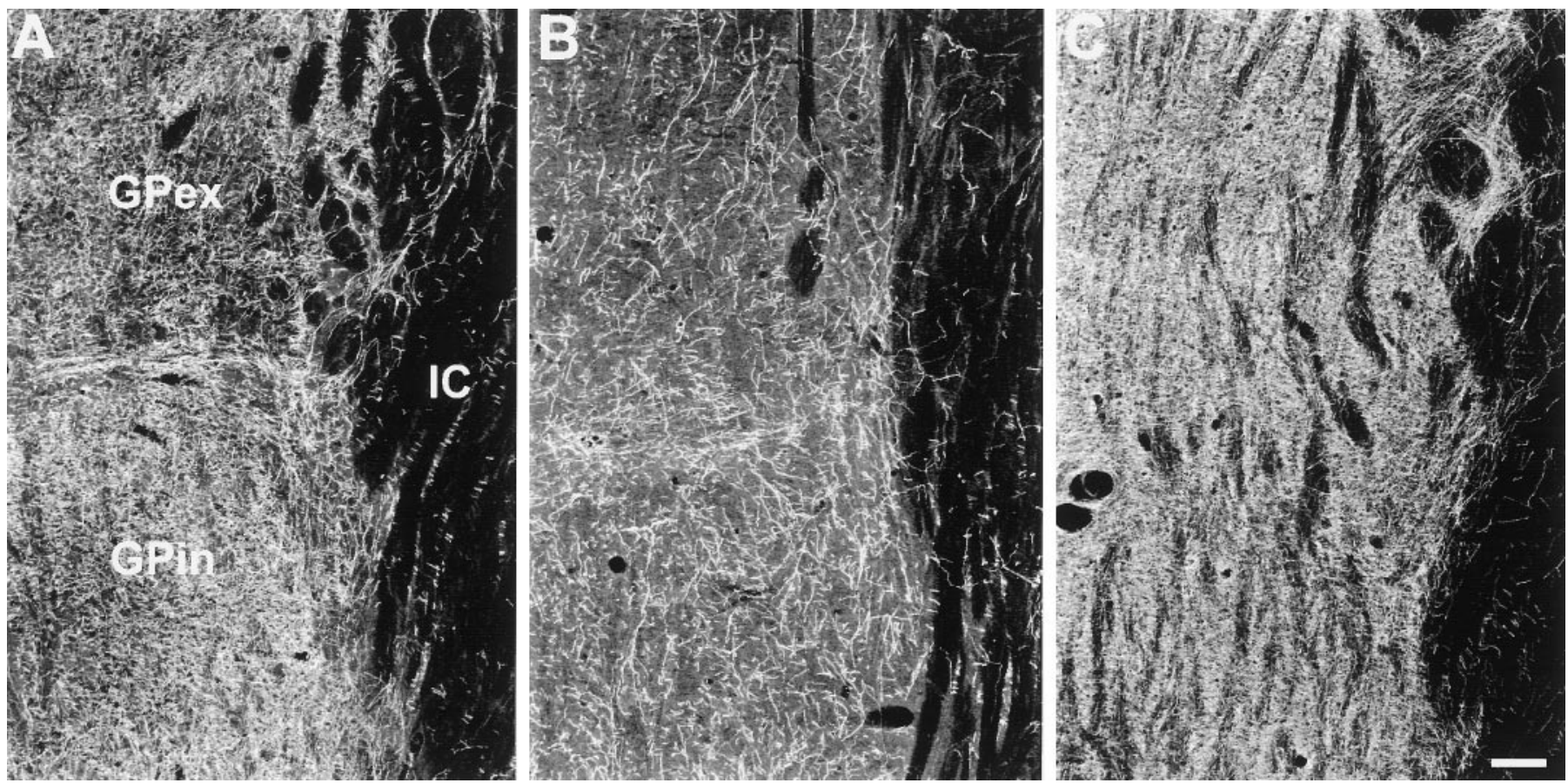

Figure 5. Dark-field photomicrograph, coronal plane, of 5-HT immunoreactive axons in the internal globus pallidus (GPin) and external globus pallidus $($ GPex) of a control monkey $(A)$, a monkey treated with MDMA 2 weeks previously $(B)$, and a monkey treated with MDMA 7 years previously $(C)$. Note apparent hyperinnervation in monkey treated with MDMA 7 years previously. IC, Internal capsule. Scale bar, $200 \mu \mathrm{m}$.

and in fact is one of the most severely lesioned regions among 2 week survivors. Seven years after MDMA treatment, there is a $16-57 \%$ reduction in the amygdala, with the exception of the central nucleus, which recovers fully (Table 2).

\section{Hypothalamus}

Two weeks after MDMA treatment, there was a slight to moderate reduction of 5-HT axons, depending on the location of the particular hypothalamic nucleus relative to the medial forebrain 

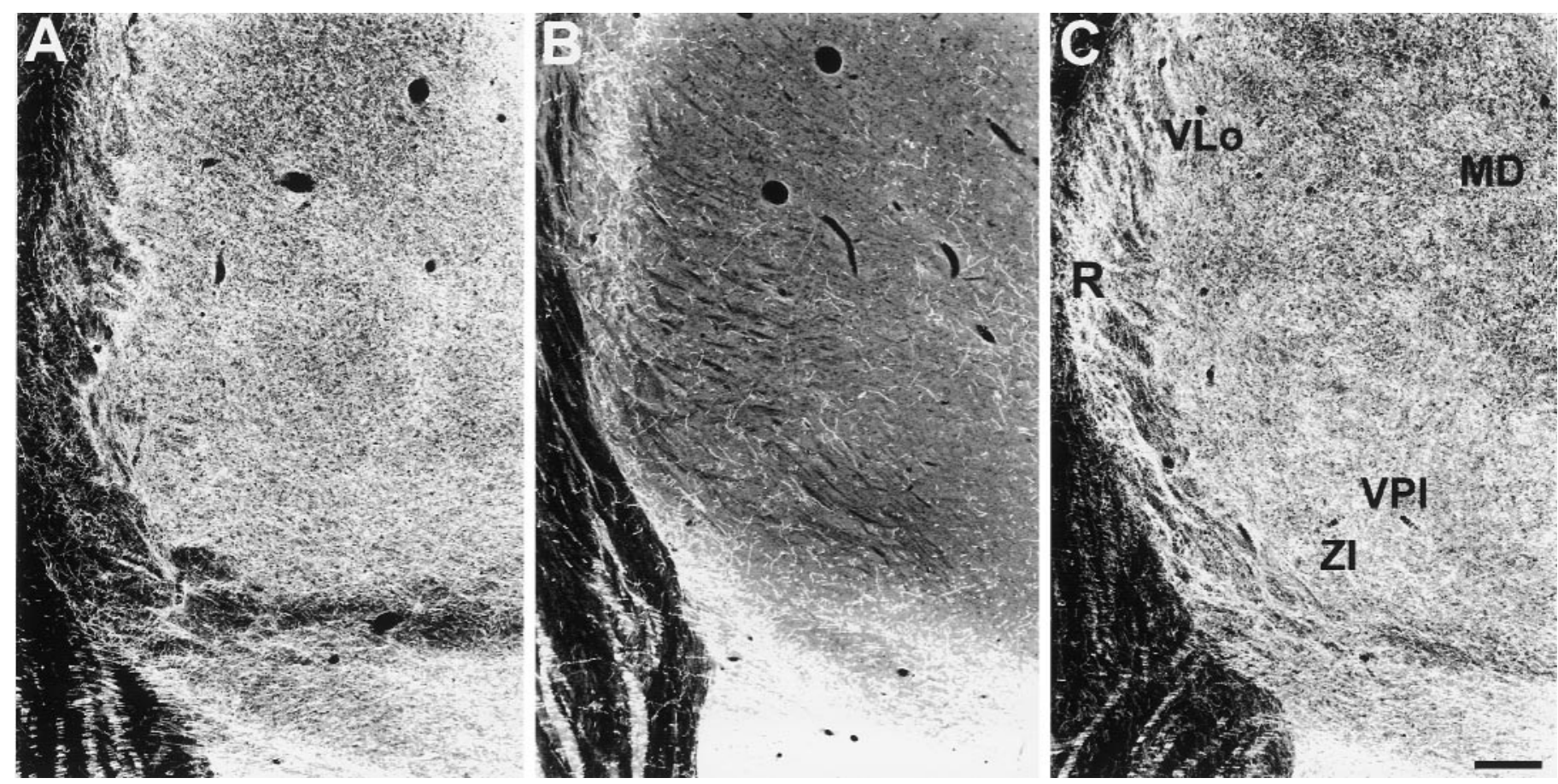

Figure 6. Dark-field photomicrograph, coronal plane, of 5-HT immunoreactive axons in the thalamus of a control monkey $(A)$, a 2 week MDMAtreated monkey $(B)$, and a 7 year MDMA-treated monkey $(C)$. A substantial reduction in 5-HT axonal density is evident 2 weeks after MDMA treatment. In contrast, 7 year survivors show complete recovery in most thalamic regions with some regions, such as the ventral anterior, the ventroposterior inferior nucleus $(V P I)$, and the reticular nucleus $(R)$ showing hyperinnervation. Scale bar, $500 \mu \mathrm{m}$.
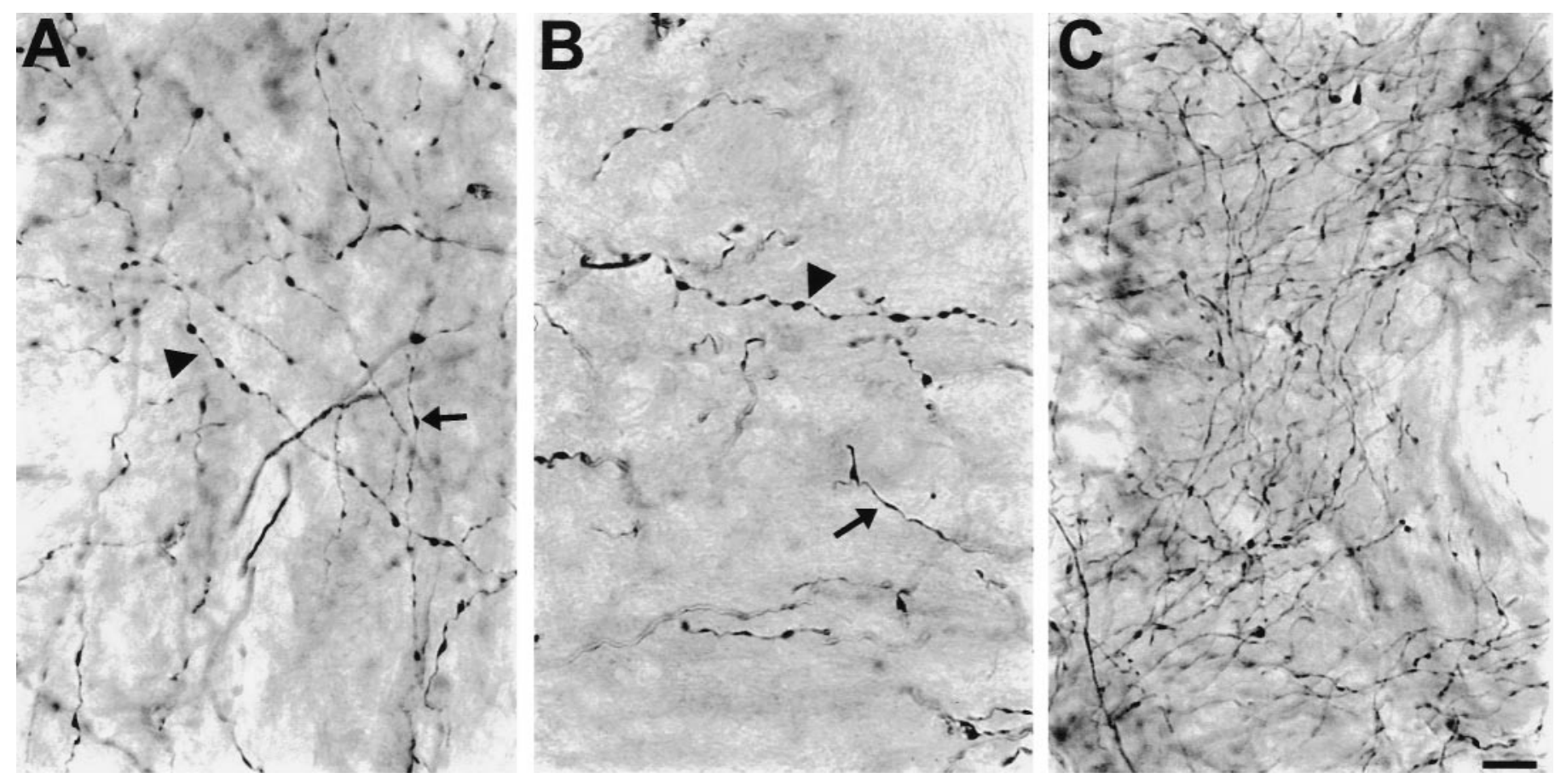

Figure 7. Bright-field photomicrograph of 5-HT immunoreactive axons in the globus pallidus of a control monkey $(A)$, a 2 week MDMA-treated monkey $(B)$, and a 7 year MDMA-treated monkey $(C)$. Fine (arrow) and beaded (arrowhead) axons are evident in the control monkey. Note reduced axon density 2 weeks after MDMA, and preponderance of fine axons 7 years after MDMA. Scale bar, $10 \mu \mathrm{m}$. 
bundle (MFB). The lateral hypothalamic nucleus appeared largely unaffected ( $6 \%$ reduction), whereas the ventromedial nucleus had a $31 \%$ reduction, the dorsomedial nucleus had a $39 \%$ reduction, and the dorsal nucleus had a $55 \%$ reduction. After a 7 year survival period, all hypothalamic nuclei examined showed evidence of complete recovery (Table 2).

\section{Thalamus}

Two week survivors show an $81-94 \%$ reduction in 5-HT axon density in the seven thalamic nuclei examined. Seven years after MDMA treatment, most of these nuclei show complete recovery of 5-HT-IR (Fig. 6, Table 2). The dorsoanterior nucleus and the lateral-dorsal nucleus are notable exceptions. Both of these nuclei have a $44 \%$ reduction in 5-HT terminals. Moreover, both of these nuclei are located adjacent to others that have recovered completely. The dorsoanterior nucleus is located next to the hyperinnervated ventroanterior nucleus, and the lateral-dorsal nucleus is adjacent to the medial-dorsal nucleus, which exhibits only a $9 \%$ loss of 5-HT axons.

\section{Axon morphology}

As described previously in rodents (Kosofsky and Molliver, 1987; Mamounas and Molliver, 1991) and nonhuman primates (Wilson et al., 1989; Hornung et al., 1990), two classes of 5-HT-IR fibers were recognized in all animals examined. Fine axons, characterized by small fusiform varicosities, were predominant throughout most cortical areas, caudate, putamen, and thalamus. Beaded axons, distinguished by large spherical varicosities, were predominant in the pyriform cortex, amygdala, and hippocampus. Regions containing roughly equal distributions of both fiber types include the septum, central amygdala, accumbens nucleus, hypothalamus, and globus pallidus.

Among 7 year survivors, 5-HT axons were typically of the predominant fiber type for that region. However, in regions exhibiting hyperinnervation, such as the globus pallidus, there was a greater preponderance of fine 5-HT axons compared with controls (Fig. 7).

\section{Raphe nuclei}

There is no apparent loss of cell bodies or change in 5-HT and tryptophan hydroxylase immunoreactivity in the dorsal, median, and B9 cell groups of 2 week and 7 year MDMA monkeys (Table 3). Examination of Nissl-stained raphe nuclei also failed to reveal any evidence of cell loss.

\section{Catecholaminergic fibers}

No difference was noted between treated and control monkeys in the density of catecholaminergic axons observed in sections processed for $\mathrm{TH}$ immunocytochemistry (data not shown).

\section{DISCUSSION}

The present results indicate that squirrel monkeys treated with MDMA and evaluated after a 7 year post-drug survival period continue to show altered brain 5-HT innervation patterns. These findings extend previous findings with MDMA (Insel et al., 1989; Ricaurte et al., 1992; Fischer et al., 1995) and other substituted amphetamines (Woolverton et al., 1989; McCann et al., 1994a,b) and suggest that MDMA-induced alterations of brain 5-HT innervation in nonhuman primates may be permanent. The present data also indicate that although some 5-HT recovery does take place over the 7 year post-drug period, this recovery is not always complete and does not occur in a number of brain regions. Whether similar enduring effects also occur in humans with a
Table 3. 5-HT-IR cell counts in the rostral raphe nuclei of squirrel monkeys treated with MDMA 2 weeks and 7 years previously

\begin{tabular}{ll} 
Raphe nucleus & Cell count \\
\hline DRN & \\
Control & $8269 \pm 1965$ \\
2 week & $8359 \pm 2183$ \\
7 year & $8996 \pm 1927$ \\
MRN & \\
Control & $7034 \pm 1364$ \\
2 week & $6366 \pm 1100$ \\
7 year & $6882 \pm 1245$ \\
\hline
\end{tabular}

history of exposure to MDMA or other substituted amphetamines remains to be determined.

Analysis of the pattern of 5-HT axonal recovery (in those brain regions where it occurs) points to several factors that appear to influence the recovery of injured 5-HT axons. One such factor is the distance of the affected 5-HT axonal terminal field from its nerve cell body of origin (Fig. 8). In particular, distal terminal fields, such as those in the dorsal neocortex, show persistent deficits, whereas more proximal terminal fields show evidence of complete reinnervation (e.g., hypothalamus) or hyperinnervation (e.g., globus pallidus). In this regard, the pattern of 5-HT axonal recovery found in the MDMA-treated primate is reminiscent of the pattern of axonal sprouting found after various experimental lesions (Wiklund et al., 1978; Bjorklund et al., 1979; Frankfurt and Azmitia, 1984; Frankfurt and Beaudet, 1987). In each of these instances, it appears that neurons have a tendency to conserve the quantity of their axon terminal fields, such that loss of synaptic contacts in distant brain regions is associated with increased synaptic contacts in more proximal brain areas (Schneider, 1973).

Although the distance of the affected terminal field from its nerve cell body of origin appears to be one factor that influences 5-HT axonal recovery after MDMA-induced injury, it is by no means an overriding factor. This is evidenced by the fact that some brain regions continue to exhibit substantial reductions in 5-HT axon density 7 years after MDMA treatment, despite the fact that they are relatively close to the rostral raphe nuclei (e.g., mammillary bodies). Moreover, there are other brain regions, such as the thalamus and amygdala, that have partially denervated nuclei juxtaposed to nuclei that are completely reinnervated (Table 2). Thus, aberrant regrowth of 5-HT axons in MDMA-treated primates results from more complex influences than those solely related to the distance of the affected terminal field from its nerve cell body of origin. Indeed, patterns of reinnervation of more distant regions may also be accounted for by multiple pathways of 5-HT innervation (Azmitia and Gannon, 1986). For example, the subiculum may receive 5-HT innervation solely from the cingulum bundle, whereas other regions of the hippocampus (CA1, $\mathrm{CA} 2, \mathrm{CA} 3, \mathrm{FD})$ receive innervation via the cingulum bundle as well as through the shorter fornix-fimbria route. In this case, the length of the cingulum bundle route could account for the larger 5 -HT deficits (20\% of control) in the subiculum of 7 year survivors. Other seemingly distant targets such as the primary visual cortex may receive input from 5 -HT pathways other than the cingulum bundle, thus resulting in greater innervation than might be expected.

Lesion size might also be expected to influence the regrowth of 


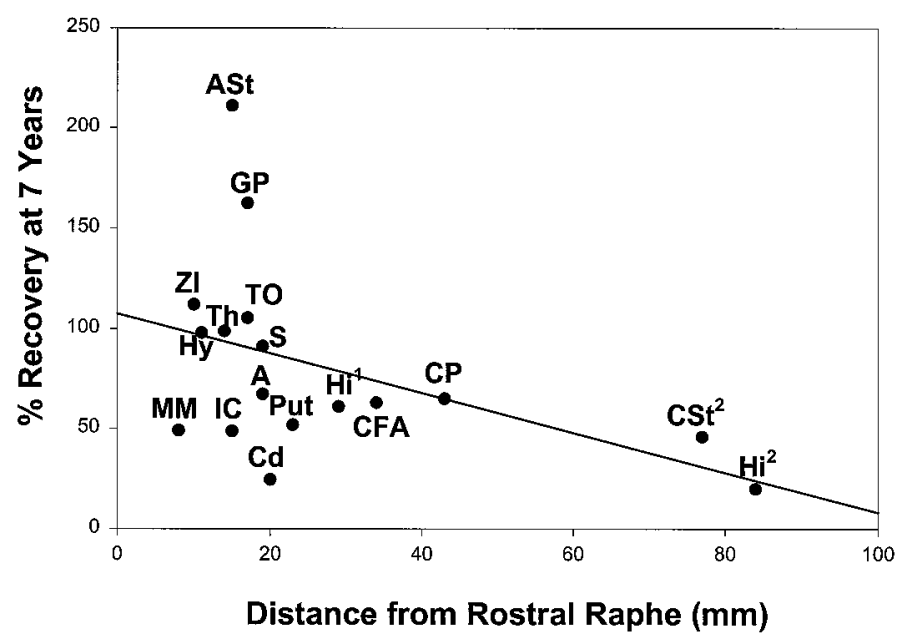

Figure 8. Relation between the distance of terminal field from the rostral raphe nuclei and recovery at 7 years. Distances were calculated using the atlases of Emmers and Akert (1963) and Gergen and MacLean (1962). ${ }^{1}$ Assumes innervation via MFB-fimbria fornix; ${ }^{2}$ assumes innervation via cingulum bundle. $r=-0.5 ; p=0.06$.

5-HT axons after MDMA injury, with more severely lesioned 5-HT axonal projections showing less recovery. Analysis of the data in Table 2 lends support to this hypothesis, because it shows that there is a near significant negative correlation $(r=-0.5, p=$ 0.07) (Fig. 9) between the size of the lesion at 2 weeks and subsequent recovery by 7 years, with more severely lesioned regions generally recovering less than less severely lesioned areas. Although this is the case for many brain regions, there are some exceptions. For example, the nucleus accumbens, olfactory tubercle, and VPI and VLo nuclei of the thalamus show severe reductions in 5-HT axon density 2 weeks after MDMA, but they are completely reinnervated or hyperinnervated 7 years later. Hence, although lesion severity appears to be an important determinant of eventual 5-HT axonal recovery, it is not the sole determining factor. The importance of lesion size as a factor that influences subsequent recovery has been recognized previously. For example, large 5-HT lesions induced by fenfluramine have been found to be followed by little, if any, long-term recovery (Zaczek et al., 1990). Conversely, smaller 5-HT lesions have been shown to be followed by complete recovery several months later (Axt et al., 1994). Although lesion size is an important determinant of subsequent recovery, it should be recognized that distant 5-HT terminal fields in the monkey brain frequently sustain more severe damage than proximal terminal fields (e.g., dorsal neocortex vs hypothalamus), making it difficult to fully distinguish between the relative importance of lesion size versus distance from the nerve cell body as factors that influence the regrowth of injured 5-HT axons.

One other factor that may influence 5-HT axonal recovery after MDMA injury is the proximity of the remaining preterminal 5-HT axons to major myelinated fiber tracts or bundles. Using the atlas of Emmers and Akert (1963), which provides a detailed description of the location of all of the myelin-containing fiber tracts in the squirrel monkey brain, it is apparent that reinnervated and/or hyperinnervated brain regions are in close proximity to myelinated fiber tracts. Examples of the apparent association between 5-HT axonal recovery and proximity to myelinated fiber bundles include the globus pallidus and its close proximity to the ansa lenticularis, and the hypothalamus and its close proximity to

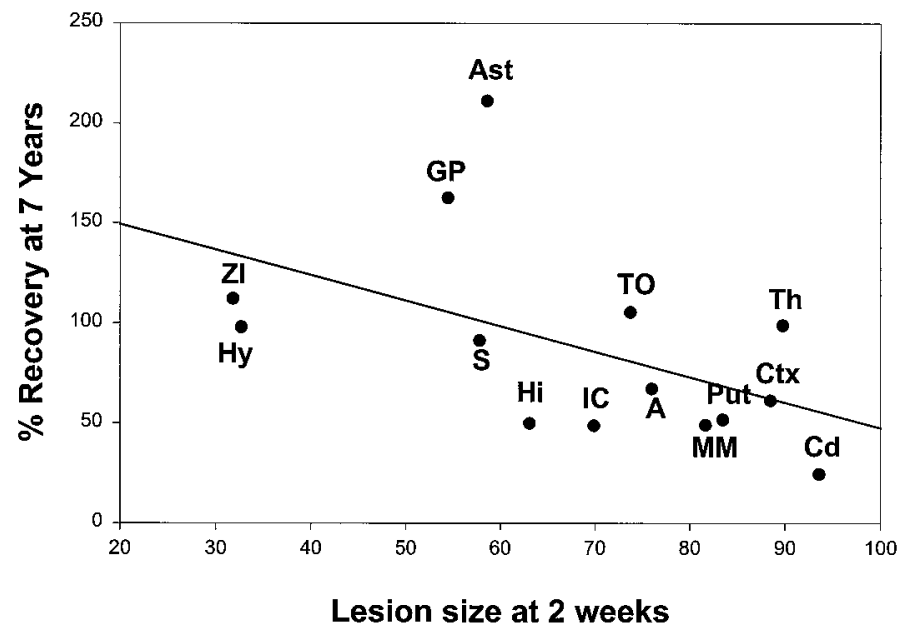

Figure 9. Relation between size of initial MDMA lesion, as gauged by the percentage of 5-HT depletion at 2 weeks, and extent of recovery of 5-HT-IR axon density 7 years later. $r=-0.5 ; p=0.07$.

the medial forebrain bundle. Thus, as first suggested by Azmitia and Gannon (1983), myelin sheaths may provide an anatomical substrate for regrowth of injured 5-HT axons. This is perhaps not surprising because in early development central 5-HT axons rapidly colonize forebrain regions by extending along newly formed myelinated pathways (e.g., the fasciculus retroflexus, stria medullaris, ansa peduncularis, and ventroamygdalofugal pathway) (Jacobs and Azmitia, 1992).

Other variables that may influence regrowth of 5-HT axons after MDMA injury, but have yet to be investigated, include proximity of injured axons to target-derived trophic factors (e.g., BDNF) (Mamounas et al., 1995), the composition of the extracellular matrix proximal to damaged axons, and the degree of myelination of the particular 5-HT axonal projection involved (Azmitia and Gannon, 1986). Additional studies are needed to better characterize these and other factors that may govern 5-HT axonal recovery after MDMA injury.

The present results also indicate that 5-HT nerve cell bodies in the rostral raphe nuclei do not sustain any measurable long-term toxic effect of MDMA (Table 3). This suggests that the aberrant 5-HT innervation found in monkeys 7 years after MDMA treatment is not caused by the loss of a particular group of 5-HT nerve cell bodies. In this regard, the hyperinnervation found in the GP is noteworthy because the GP normally has an admixture of thin and varicose fibers (Lavoie and Parent, 1990), indicating that it receives innervation from both the dorsal raphe nucleus (DRN) and median raphe nucleus, respectively (Kosofsky and Molliver, 1987; Wilson et al., 1989; Hornung et al., 1990; Mamounas and Molliver, 1991). The fact that 7 years after treatment there is a striking preponderance of fine 5-HT axons in the GP of the MDMA-treated monkey suggests that the observed hyperinnervation originates primarily from the DRN. The occurrence of such axonal sprouting in other brain regions of the MDMAtreated primate merits further investigation.

In summary, the present results indicate that MDMA-induced 5-HT neural injury in nonhuman primates lasts for at least 7 years and may well be permanent. In addition, the present results point to several factors that appear to influence axonal recovery after MDMA injury, including the distance of the damaged terminal field from its nerve cell body of origin, the size or severity of the initial lesion, and the proximity of the injured axons to myelinated 
fiber tracts. Additional studies are needed to assess the relative importance of each of these factors and to identify other variables that may influence recovery of 5-HT axons after MDMA injury. Finally, it will be important to use newly developed positron emission tomography imaging techniques (McCann et al., 1998) to determine whether the present findings generalize to humans with a history of recreational MDMA use.

\section{REFERENCES}

Adelekan M, Adlaf E, Alkott A, Banaag C, Bem P (1997) Epidemiology and social context of amphetamine-type stimulant use. In: Amphetamine-type stimulants: a report from the WHO meeting on amphetamines, MDMA and other psychostimulants, Geneva, pp 12-15. Programme on Substance Abuse, Division of Mental Health and Prevention of Substance Abuse. World Health Organization.

Axt K, Mamounas L, Molliver M (1994) Structural features of amphetamine neurotoxicity in the brain. In: Amphetamine and its analogs: neuropsychopharmacology, toxicology and abuse (Cho A, Segal D, eds), pp 315-370. New York: Academic.

Azmitia EC, Gannon PJ (1983) The ultrastructural localization of serotonin immunoreactivity in myelinated and unmyelinated axons within the medial forebrain bundle of the rat and monkey. J Neurosci 3:2083-2090.

Azmitia EC, Gannon PJ (1986) The primate serotonergic system: a review of human and animal studies and a report on Macaca fascicularis. Adv Neurol 43:407-468.

Azmitia EC, Murphy RB, Whitaker-Azmitia PM (1990) MDMA (Ecstasy) effects on cultured serotonin neurons: evidence for $\mathrm{Ca}^{+2}$-dependent toxicity linked to release. Brain Res 510:97-103.

Battaglia G, Yeh SY, O'Hearn E, Molliver ME, Kuhar MJ, DeSouza EB (1987) 3,4-Methylenedioxymethamphetamine and 3,4-methylenedioxyamphetamine destroy serotonin terminals in rat brain: quantification of neurodegeneration by measurement of $\left[{ }^{3} \mathrm{H}\right]$ paroxetine-labeled serotonin uptake sites. J Pharmacol Exp Ther 242:911-916.

Battaglia G, Yeh SY, DeSouza EB (1988) MDMA-induced neurotoxicity: parameters of degeneration and recovery of brain serotonin neurons. Pharmacol Biochem Behav 29:269-274.

Baum RM (1985) New variety of street drugs poses growing problem. Chem Eng News 63:7-16.

Bjorklund A, Wiklund L (1980) Mechanisms of regrowth of the bulbospinal serotonin system following 5,6-dihydroxytryptamine-induced axotomy: biochemical correlates. Brain Res 191:109-127.

Bjorklund A, Wiklund L, Descarries L (1979) Regeneration and plasticity of central serotonergic neurons: a review. J Physiol (Lond) 77:247-255.

Commins DL, Vosmer G, Virus R, Woolverton W, Schuster C, Seiden L (1987) Biochemical and histological evidence that methylenedioxymethylamphetamine (MDMA) is toxic to neurons in the rat brain. J Pharmacol Exp Ther 241:338-345.

De Souza EB, Battaglia G, Insel T (1990) Neurotoxic effects of MDMA on brain serotonin neurons: evidence from neurochemical and radioligand binding studies. Ann NY Acad Sci 600:682-698.

Doblin R (1989) Risk assessment: the FDA and MDMA research. In: Ecstasy: the MDMA story (Eisner B, ed), pp 163-170. Berkeley, CA: Ronin.

Emmers R, Akert K (1963) A stereotaxic atlas of the brain of the squirrel monkey (Saimiri sciureus). Madison, WI: University of Wisconsin.

Fischer CA, Hatzidimitriou G, Katz JL, Ricaurte GA (1995) Reorganization of ascending serotonin axon projections in animals previously exposed to the recreational drug 3,4-methylenedioxymethamphetamine. J Neurosci 15:5476-5485.

Frankfurt M, Azmitia E (1984) Regeneration of serotonergic fibers in the rat hypothalamus following unilateral 5,7-dihydroxytryptamine injection. Brain Res 298:273-282.

Frankfurt M, Beaudet A (1987) Ultrastructural organization of regenerated serotonin axons in the dorsomedial hypothalamus of the adult rat. J Neurocytol 16:799-809.

Gergen JA, MacLean PD (1962) A stereotaxic atlas of the squirrel monkey's brain (Saimiri sciureus). United States Department of Health Education and Welfare, Public Health Service Publication 933.

Hornung JP, Fritschy JM, Tork I (1990) Distribution of two morphologically distinct subsets of serotoninergic axons in the cerebral cortex of the marmoset. J Comp Neurol 297:165-181.
Insel TR, Battaglia G, Johannessen JN, Marra S, De Souza EB (1989) 3,4-Methylenedioxymethamphetamine ("ecstasy") selectively destroys brain serotonin terminals in rhesus monkeys. J Pharmacol Exp Ther 249:713-720.

Jacobs BL, Azmitia EC (1992) Structure and function of the brain serotonin system. Physiol Rev 72:165-229.

Johnston L, Bachman J, O'Malley P (1996) National survey results on drug use from the monitoring the future study. National Institutes on Drug Abuse, 1975-1994. Vol 2: College students and young adults. NIH Publication No. 96-4027.

Johnston L, Bachman J, O'Malley P (1998) National survey results on drug use from the monitoring the future study. National Institutes on Drug Abuse, 1975-1995. Vol 2: College students and young adults. NIH Publication 98-4346.

Kosofsky B, Molliver M (1987) The serotoninergic innervation of the cerebral cortex: different classes of axon terminals arise from dorsal and median raphe nuclei. Synapse 1:153-168.

Lavoie B, Parent A (1990) Immunohistochemical study of the serotoninergic innervation of the basal ganglia of the squirrel monkey. J Comp Neurol 299:1-16.

Lew R, Sabol KE, Chou C, Vosmer GL, Richards J, Seiden LS (1996) Methylenedioxymethamphetamine-induced serotonin deficits are followed by partial recovery over a 52-week period. Part II: Radioligand binding and autoradiography studies J Pharmacol Exp Ther 276:855-865.

Mamounas LA, Molliver ME (1991) Dual serotonergic projections to forebrain in the rat: morphologically distinct $5-\mathrm{HT}$ axon terminals exhibit differential vulnerability to neurotoxic amphetamine derivatives. J Comp Neurol 314:558-586.

Mamounas LA, Blue ME, Siuciak JA, Altar CA (1995) BDNF promotes the survival of sprouting serotonergic axons in rat brain. J Neurosci 15:7929-7939.

McCann UD, Ridenour A, Shaham Y, Ricaurte GA (1994a) Serotonin neurotoxicity after $( \pm)$ 3,4-methylenedioxymethamphetamine (MDMA; "Ecstasy"): a controlled study in humans. Neuropsychopharmacology 10:129-138.

McCann UD, Hatzidimitriou G, Ridenour A, Fisher C, Yuan J, Katz J, Ricaurte GA (1994b) Dexfenfluramine and serotonin neurotoxicity: further preclinical evidence that clinical caution is indicated. J Pharmacol Exp Ther 269:792-798.

McCann UD, Szabo Z, Scheffel U, Dannals RF, Ricaurte GA (1998) Positron emission tomographic evidence of toxic effect of MDMA ("Ecstasy") on brain serotonin neurons in human beings. Lancet 352:1433-1437.

Molliver ME, Berger UV, Mamounas LA, Molliver DC, O'Hearn EG, Wilson MA (1990) Neurotoxicity of MDMA and related compounds: anatomic studies. Ann NY Acad Sci 600:640-664.

O’Hearn EG, Battaglia G, De Souza EB, Kuhar MJ, Molliver ME (1988) Methylenedioxyamphetamine (MDA) and methylenedioxymethamphetamine (MDMA) cause selective ablation of serotonergic axon terminals in forebrain: immunocytochemical evidence for neurotoxicity. J Neurosci 8:2788-2803.

Ricaurte GA, Forno LS, Wilson MA, DeLanney LE, Irwin I, Molliver ME, Langston JW (1988a) ( \pm )3,4-Methylenedioxymethamphetamine (MDMA) selectively damages central serotonergic neurons in nonhuman primates. JAMA 260:51-55.

Ricaurte GA, DeLanney LE, Irwin I, Langston JW (1988b) Toxic effects of MDMA on central serotonergic neurons in the primate: importance of route and frequency of drug administration. Brain Res 446:165-168.

Ricaurte GA, Martello AL, Katz JL, Martello MB (1992) Lasting effects

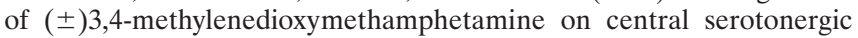
neurons in non-human primates: neurochemical observations. J Pharmacol Exp Ther 261:616-622.

Sabol KE, Lew R, Richards JB, Vosmer GL, Seiden LS (1996) Methylenedioxymethamphetamine-induced serotonin deficits are followed by partial recovery over a 52-week period. Part I: synaptosomal uptake and tissue concentrations. J Pharmacol Exp Ther 276:846-854.

Saunders N (1995) Ecstasy and the dance culture. London: Nicholas Saunders.

Scanzello CR, Hatzidimitriou G, Martello AL, Katz JL, Ricaurte GA (1993) Serotonergic recovery after $( \pm) 3$,4-(methylenedioxy) methamphetamine injury: observations in rats. $\mathrm{J}$ Pharmacol Exp Ther 264:1484-1491. 
Schmidt CJ (1987) Neurotoxicity of the psychedelic amphetamine, methylenedioxymethamphetamine. J Pharmacol Exp Ther 240:1-7.

Schmidt CJ, Taylor VL (1987) Depression of rat brain tryptophan hydroxylase activity following the acute administration of methylenedioxymethamphetamine. Biochem Pharmacol 36:4095-4102.

Schneider GE (1973) Early lesions of the superior colliculus: factors affecting the formation of abnormal retinal projections. Brain Behav Evol 8:73-109.

Slikker W, Ali SF, Scallet C, Frith CH, Newport GD, Bailey JR (1988) Neurochemical and neurohistological alterations in the rat and monkey produced by orally administered methylenedioxymethamphetamine (MDMA). Toxicol Appl Pharmacol 94:448-457.

Stone DM, Stahl DS, Hanson GL, Gibb JW (1986) The effects of 3,4methylenedioxymethamphetamine (MDMA) and 3,4-methylenedioxyamphetamine on monoaminergic systems in the rat brain. Eur J Pharmacol 128:41-48.

Wiklund L, Bjorklund A, Nobin A (1978) Regeneration of serotonin neurons in the rat brain after 5,6-dihydroxytryptamine-induced axotomy. Ann NY Acad Sci 305:370-384.

Wilson MA, Ricaurte GA, Molliver ME (1989) Distinct morphological classes of serotonergic axons in primates exhibit differential vulnerability to the psychotropic drug 3,4-methylenedioxymethamphetamine. Neuroscience 28:121-137.

Wilson MA, Mamounas LA, Fasman KA, Axt KJ, Molliver ME (1993) Reactions of 5-HT neurons to drugs of abuse: neurotoxicity and plasticity. NIDA Research Monograph 136:155-187.

Woolverton WL, Ricaurte GA, Forno LS, Seiden LS (1989) Long-term effects of chronic methamphetamine administration in rhesus monkeys. Brain Res 486:73-78.

Zaczek R, Battaglia G, Culp S, Appel NM, Contrera JF, De Souza EB (1990) Effects of repeated fenfluramine administration on indices of monoamine function in rat brain: pharmacokinetic, dose response, regional specificity, and time course data. J Pharmacol Exp Ther 253:104-112. 